\title{
MONUMENTOS ESPAÑOLES EN CARICATURA, 1860-1920
}

\section{SPANISH MONUMENTS IN CARICATURE, 1860-1920}

\author{
Carlos Reyero \\ Universidad Autónoma de Madrid. España \\ carlos.reyero@uam.es
}

\begin{abstract}
Este texto analiza caricaturas de monumentos publicadas en los periódicos de Madrid y Barcelona. El argumento se centra en los procedimientos de alteración de la imagen. Estos cambios no solo están condicionados por el sentido del humor, sino también por factores estéticos y políticos.

Palabras clave: parodia en arte; escultura urbana; sátira política; crítica de arte; prensa.
\end{abstract}

This text analyzes caricatures of monuments published in Madrid and Barcelona newspapers. The argument focuses on image alteration procedures. These changes are not only conditioned by the sense of humor, but also by aesthetic and political factors.

Key words: parody in art; urban sculpture; political satire; art criticism; press.

\section{INTRODUCCIÓN}

La caricatura de obras de arte-de sus artífices y modos de producción, de sus públicos y escenarios expositivos- $\mathrm{y}$, en general, el uso paródico de reproducciones artísticas en entornos radicalmente diferentes a los que fueron concebidas es un fenómeno bien conocido ${ }^{1}$. Forma parte, como se sabe, de la trasformación del

* Este trabajo se ha realizado dentro del proyecto de investigación «Madrid capital: la utopía liberal» CMM-COURT-TOURIST-CM (Referencia H2015/HUM-3415), financiado por la Comunidad de Madrid.

${ }^{1}$ HUTCHEON, Linda: A Theory of Parody. The Teachings of Twentieth-Century Art Forms. Urbana-Chicago, 1985; "Pastiches et parodies de tableaux de maîtres", Ridiculosa, 3, 1996; y MONCELET, Christian: "Les parodies d'images célèbres", Ridiculosa, 8, 2001, pp. 194-195. Hay monografías sobre obras concretas, por ejemplo: JACOBS, Helmut C.: El sueño de la razón. El capricho 43 de Goya en el are visual, la literatura y la música. Madrid, 2011; y MAELL, Erik (coord.): Mona Lisa reimagined. Nueva York, 2015. 
arte y su circunstancia en un producto de consumo visual, sometido, por tanto, a la misma manipulación que cualquier otro tipo de imágenes. De todos modos, no recibirían una mirada selectiva de no remitir a objetos previamente considerados distintos. En la interpretación caricaturesca o paródica del arte se dialoga con esa distinción, sin la cual la nueva imagen carecería de la capacidad de sorpresa o provocación que pretende, por el mero hecho de aparecer en un contexto no distinguido. Por eso, más allá de su apreciación como productos de una subcultura o integrados en una visualidad indiferenciada, en este tipo de imágenes emerge la tensión de lo artístico como no artístico o, al menos, de la complejidad intelectual y estética de una imagen frente a su banalización en otra. A diferencia del creador que, por el hecho de serlo, convierte en arte todo lo que toca, el caricaturista tiende a eliminarlo, en tanto que borra el aura de artisticidad del motivo elegido. Sin embargo, en esa intervención se encierra una actitud inquietante porque solo lo serio es sujeto de broma. En última instancia, la risa siempre es ambigua. Por eso, estas imágenes, en apariencia secundarias o subsidiarias de otras, nos hablan sobre modos de ver, interiorizar, usar y recordar el arte. En definitiva, sobre la aceptación y la fortuna crítica de los objetos parodiados en términos visuales.

La costumbre no es reciente. En la medida que el arte ha aludido a un poder o ha encarnado un mito, siempre ha sido objeto de ataque. Antes de que en el siglo XIX la práctica de reírse de él -o con él- se extendiese, ya se habían producido estampas satíricas que ridiculizaban la retórica que le rodeaba ${ }^{2}$. Pero es verdad que, mediado aquel siglo, la caricatura del llamado "mundo del arte" y, en especial, la parodia visual de obras coetáneas en el momento de su exposición, llegó a convertirse en una práctica tan habitual que resulta inseparable de su recepción ${ }^{3}$. Esa práctica, desarrollada de forma paralela al auge de los salones parisinos, llegó a España más tarde ${ }^{4}$. Al mismo tiempo, la estatuaria recibió también una atención específica por parte de los humoristas gráficos ${ }^{5}$. A este respecto, cabe diferenciar las caricaturas ligadas a monumentos reales, que es la cuestión tratada aquí, del

2 ARNAULDET, Thomas: Notes sur les estampes satiriques, bouffonnes ou singulières relatives à l'art et aux artistes français pendant les XVIIe et XVIIIe siècles. París, 1859.

${ }^{3}$ BARIDON, Laurent y GUÉDRON, Martial: "Caricaruter l'art: usages et fonctions de la parodie", en LE MEN, Ségolène (dir.): L'Art de la caricature. París, 2011, pp. 87-108. http://books.openedition.org/pupo/2216 (Consultado el 22-11-2016)

${ }^{4}$ REYERO, Carlos: "El arte desacralizado: La Avispa (1883-1891)", en V congrès espanyol d'història de l'art. Vol. 3. Barcelona, 1987, pp. 83-90; y CAPARRÓS, Lola y GAMONAL TORRES, Miguel Ángel: "Gedeón en las exposiciones nacionales de Bellas Artes (1897-1912)", Cuadernos de Arte de la Universidad de Granada, 41, 2010, pp. 249-268.

5 BARIDON, Laurent: "Dantan, le caricaturiste de la statuomanie", Ridiculosa, 13, 2006, pp. 127-143. http://www.caricaturesetcaricature.com/article-13884914.html (Consultado el 22-11-2016); BEAUSIRE, Alain y VILAIN, Jacques: Rodin et la caricature. París, 1990; y WAGNER, Anne M.: "Rodin's Reputation", en TOMLINSON, Janis (ed.): Readings in Nineteenth-Century Art. New Jersey, 1996, pp. 246-277. 
uso paródico de la fórmula rememorativa como tal, un argumento que tiene otro alcance $^{6}$. En todo caso, en virtud de la propia naturaleza pública y permanente de los monumentos, estos motivaron al caricaturista tanto por su carácter de piezas nuevas como por el hecho de convertirse de inmediato en iconos urbanos.

Las fuentes tenidas en cuenta para realizar este trabajo proceden de una selección de caricaturas aparecidas en periódicos ilustrados de Barcelona y de Madrid. Se refieren a monumentos levantados en esas ciudades, salvo dos casos de Sevilla, uno de Bilbao y otro de Granada, así como otro destinado a la ciudad de Paraná (Argentina), que fueron parodiados durante el periodo seleccionado, una época en la que esta modalidad de actuación artística en el espacio público adquirió singular importancia ${ }^{7}$.

Para que una caricatura funcione es preciso que la obra a la que remite sea bien identificada. Por lo tanto, el método para su análisis parte de la comparación formal y funcional entre el modelo y su parodia. Se trata de distinguir, en primer lugar, los distintos procedimientos de alteración de la imagen original. En segundo lugar, detectar la relación existente entre la modificación y el sentido de la parodia. Todo ello ha de conducirnos a desentrañar funciones visuales de la caricatura, las razones de su éxito y las consecuencias en la percepción de los monumentos.

\section{LOS PERSONAJES COBRAN VIDA}

El mito de Pigmalión está ligado a la esencia misma de la escultura como arte. Pero no es el amor lo que insufla vida -o apariencia de vida- a las figuras de los pedestales cuando se caricaturizan, sino, más bien, la falta de estima por quienes deberían apreciarlas: los ciudadanos. El procedimiento sugiere, pues, un cierto desapego por los monumentos o por los personajes representados en ellos. Por tanto, ha de entenderse como una denuncia.

Es el caso del monumento a Fernando el Católico en la plaza Real de Barcelona, cuya primera piedra se puso el 10 de noviembre de 1850. Inacabado, cuando la reina Isabel II visitó la ciudad en 1860, se colocó de forma provisional una estatua en yeso, que fue deteriorándose. En 1863 no quedaba más que el pedestal, retirado definitivamente en $1868^{\circ}$. Las obras de la plaza y el desmantelamiento del

${ }^{6}$ BAZÁN DE HUERTA, Moisés: "El monumento público visto por el humor gráfico”, Norba-Arte, XXV, 2005, pp. 303-330. Algunos estudios específicos sobre monumentos también han tenido en cuenta imágenes de la cultura popular: MERINO CALVO, José Antonio: El Monumento a las Cortes, Constitución y Sitio de Cádiz. Cádiz, 2012.

${ }^{7}$ REYERO, Carlos: El monumento conmemorativo en España. La edad de oro del monumento público, 1820-1914. Madrid, 1999; y GARCÍA GUATAS, Manuel: La imagen de España en la escultura pública, 1875-1935. Zaragoza, 2009.

${ }^{8}$ LECEA, Ignasi y otros: Art públic de Barcelona. Barcelona, 2009, p. 114. 
monumento fueron objeto de crítica: con expresión cariacontecida el monarca camina delante de su caballo, junto a las rejas del pedestal de que acaba de bajarse, para marcharse de allí, con un brazo roto (Figura 1). Debajo se lee: "No culpes, D. Fernando, al pueblo catalán: los que tan mal te han tratado son..."9. Meses después, se atribuye al viento la caída de jinete y caballo del pedestal. El rótulo parece aludir a que la obra no tenía calidad artística: "El viento vengó a las bellas artes SIC TRANSIT GLORIA MUNDI"10. Finalmente la escultura vive en el otro mundo: el rey Católico saluda entre nubes a un genio de la ciudad de Villanueva (sic), que, tras haber sido colocada en su pedestal, también desapareción ${ }^{11}$.

Otras veces sirve para acusar al poder municipal de que no tiene en cuenta el apego popular que despiertan los monumentos. En 1870 se ironiza sobre la permanencia en el barrio de la Barceloneta de Barcelona de uno de sus habitantes más destacados, el Neptuno que entonces estaba en el Muelle de la Riba o del Rebaix $^{12}$ : se resiste a marcharse a Montalegre, como otros vecinos del barrio, obligados por el Ayuntamiento ${ }^{13}$. Con motivo del desmantelamiento en 1877 de la Font del Vell, un monumento situado en la Rambla de Barcelona y dedicado a Minerva como personificación de la ciudad, los personajes principales del mismo, Minerva y una alegoría del río Llobregat, que estaban en el pedestal, aparecen junto a distintos tipos populares, que reclaman que no se vayan ${ }^{14}$. Unos años antes, como el monumento parecía sentenciado, se había reinterpretado como un panteón funerario ${ }^{15}$.

La iconografía que adoptan los personajes en la escultura pública llegó a considerarse una especie de garantía de realidad. Cristóbal Colón vuelve a la vida con la apariencia con la que le imaginaron Jerónimo Suñol o Rafael Atché en los monumentos de Madrid y Barcelona. De la conmemoración madrileña se publicaron, nada más erigirse, varias caricaturas, en algunas de las cuales se recurre al tipo que sufre, por ejemplo, la estrechez del espacio en el que fue obligado a

${ }^{9}$ El Pájaro Azul, 20 de julio de 1861, p. 9.

${ }_{10}$ El Pájaro Azul, 7 de diciembre de 1861.

${ }_{11}$ El Pájaro Azul, 18 de octubre de 1862, pp. 6-7. Debe de referirse a la escultura de un Genio, realizada por Andreu Aleu para una fuente en Vilanova i la Geltrú, que estuvo en la rambla de esta ciudad. http://www.diba.cat/documents/429042/e647e7a1-203f-42fdae08-5a866c41897c (Consultado el 22-11-2016).

12 Obra de Adrià Ferran y Celedoni Guixà, fue colocado allí por la Junta de obras del Puerto de Barcelona, donde estuvo hasta 1919. Tras sucesivos traslados, fue ubicada en 1983 en la plaza de la Mercé.

13 La Campana de Gracia, 30 de octubre de 1870.

${ }^{14}$ La Campana de Gracia, 21 de enero de 1877. La estatua de Minerva se guarda en los almacenes municipales, mientras la alegoría del río Llobregat se exhibe como monumento autónomo en la plaza de Sants. OJUEL, María: "L'estàtua al·legòrica de Minerva", L'Avenç, 365, 2010, pp. 56-58.

15 Lo Xanguet, 1872, s. p. 
permanecer ${ }^{16}$ (Figura 2). El Colón de Barcelona revivió en las revistas satíricas de la ciudad a lo largo de mucho tiempo: en general, el personaje goza de un prestigio moral que le permite discutir con las autoridades municipales sobre asuntos de actualidad, generalmente relacionados con gastos excesivos, o arrogarse la capacidad de reflexionar por encima de las circunstancias mundanas ${ }^{17}$.

Como individuos vivos, los personajes de los monumentos reaccionan ante lo que ocurre en la ciudad. En Madrid, el Ángel caído de Ricardo Bellver, colocado como monumento en el parque del Retiro, se enjuga las lágrimas de dolor con un pañuelo, a causa del baile que tuvo lugar allí, según la revista que lo caricaturiza, "nada más tonto, ni más insustancial, ni menos interesante"18. En Barcelona, una revista se imagina una asamblea de estatuas "aprovechando el momento en que la ciudad queda sin nadie que la vigile [...] y López va a avisar al ángel del Plaza de Palacio, y este a Prim, y Prim a las demás estatuas del parque, llegando en cuatro galopadas hasta la Rambla de Cataluña para poner al tanto de la cosa a Clavé y a Güell y aprovechando el viaje para convocar a Fivaller y a Don Jaime en el Ayuntamiento". Cuando todos están reunidos toma la palabra Colón para quejarse de que quiten los adornos de los monumentos, y propone una huelga de estatuas $^{19}$. Se ilustra con caricaturas de los monumentos a Colón, Güell, Roger de Lluria, Casanova, Jaime I y la Dama del Paraguas.

Quienes observan los monumentos sienten que los personajes están tan vivos como ellos mismos. Unas veces porque se admiran y otras porque sobrecogen. Ante las estatuas del Saló Sant Joan de Barcelona, un guardia municipal, con el rostro aterrorizado, pronuncia la célebre frase del Tenorio: "No, no me causan pavor/ vuestros semblantes esquivos" ${ }^{20}$. Se caricaturiza el monumento a Güell porque el personaje aparece "demasiado" embozado en su capa y parece que se tapa del frío ${ }^{21}$. Frederic Soler tiene que soportar la lluvia ${ }^{22}$. Vivo se caricaturiza a

${ }^{16}$ La Caricatura, 25 de mayo de 1884.

${ }_{17}$ Recogidos con anterioridad por REYERO, Carlos: "Propaganda, parodia, imagen de marca. La metamorfosis gráfica del monumento a Colón de Barcelona entre dos exposiciones, 1888-1929", en HERNÁNDEZ LATAS, José Antonio (ed.): El arte público a través de su documentación gráfica y literaria. Homenaje a Manuel García Guatas. Zaragoza, 2015, pp. 35-54.

18 Juan Rana, 16 de julio de 1897.

19 "Reunió d'estatues", $C u$-Cut, 2 de enero de 1902, pp. 6-7. CAPDEVILA, Jaume (coord.): Cu-Cut! Sátira política en temps trasblasats (1902-1912). Barcelona, 2012, pp. 140-141.

${ }^{20}$ L'Esquella de la Torratxa, 22 de julio de 1904. Ilustración de Josep Costa Ferrer, Picarol. CADENA, Josep Maria: Barcelona vista pels seus dibuixants, 1888-1929. Barcelona, 2014, p. 12.

${ }^{21}$ Cu-Cut!, 27 de noviembre de 1902, p. 803. El dibujo es de Gaietà Cornet i Palau. CADENA, J. M.: Barcelona vista..., op. cit., p. 56.

${ }_{22}^{2} L^{\prime} A v i, 8$ de enero de 1907. 
Clavé, en lo alto de su monumento, en actitud de dirigir un coro: opina que el mejor regalo que podrían hacerle era sacarle de donde está23 ${ }^{2}$ Es frecuente ver a Rafael Casanova como un personaje que vive la realidad. Lee el número 100 de la revista $\mathrm{Cu}$-Cut ${ }^{24}$ o dirige la palabra al alcalde para preguntarse si él es el conseller en cap, a lo que este responde que ahora los consellers no tienen ni pies ni cabeza $^{25}$. El gesto del personaje se modifica ${ }^{26} \mathrm{y}$ adopta diversos papeles de consuelo, ya sea para solidarizarse con Bélgica ${ }^{27}$ o para acoger a Maciàa ${ }^{28}$.

El contraste entre el artista y la grandeza de su obra era un recurso habitual en el imaginario romántico, que en las publicaciones humorísticas puede relacionarse con una manera de aludir a otra forma de vida. En 1910 Gedeón caricatura a Benlliure junto a las patas de la escultura de un caballo, publicada "con el solo objeto de que, cuando llegue a Buenos Aires el original, puedan compararse" 29 . Debe tratarse, lógicamente, de la estatua ecuestre del monumento al general Urquiza, inaugurado en la avenida Rivadavia de Paraná en 1920, cuyo pedestal es obra de Querol.

\section{REINTERPRETACIONES}

La modificación visual del monumento tiende a percibirse como un pretexto caricaturesco colateral, concebido para provocar una sonrisa, pero esconde formas de hacer crítica política y artística. El monumento a Fernando el Católico en la Plaza Real de Barcelona es reinterpretado como un monumento al alcalde a lomos de un burro. En el pedestal aparece la siguiente inscripción: "AQUÍ YACEN/ LAS BELLAS ARTES/ EL SENTIDO COMÚN/ LA ACTIVIDAD/ MUNICIPAL/ Y/ MUCHAS COSAS/ MAS/ R.I.P". Y en la base: "OSARIO/ DE D. FERNANDO EL CA-/ TOLICO Y SU JAMELGO" ${ }^{30}$. También se reinterpreta

${ }^{23}$ L'Esquella de la Torratxa, 10 de noviembre de 1916. El dibujo es de Josep Costa i Ferrer, Picarol. CADENA, J. M.: Barcelona vista..., op. cit., p. 45.

${ }^{24}$ Cu-Cut!, 26 de noviembre de 1903. CAPDEVILA, J. (coord.): Cu-Cut! Sátira política..., op. cit., p. 164.

${ }^{25} \mathrm{Cu}$-Cut!, 6 de septiembre de 1906. Juego de palabras intraducible por la homonimia de la palabra cap (cabeza).

${ }^{26}$ L'Esquella de la Torratxa, 11 de septiembre de 1908. CADENA, J. M.: Barcelona vista..., op. cit., p. 43.

$27 \mathrm{http} / / /$ arxiuhistoric.bcn.cat/onzesetembre/es/1914/la-ereccion-del-monumento-arafael-casanova (Consultado el 22-11-2016)

${ }^{28}$ CAPDEVILA, Jaume: L'Esquella de la Torratxa. 60 anys d'història catalana (18791939). Barcelona, 2013, p. 150.

${ }^{29}$ Gedeón, 27 de marzo de 1910.

${ }^{30}$ El Tiburón, 1863, s. p. 
como "Un caballo con tres PIES Y DOS CABEZAS" 31 y como una pajarita de papiroflexia que cabalga un monigote ${ }^{32}$.

Con motivo de la falta de fondos para levantar un monumento a Colón en Barcelona se parodia el monumento al marqués de Comillas, ante el que el navegante pide limosna como un pordiosero. Lo interesante de esta caricatura es que, además de reducir el pedestal para sugerir el diálogo entre los dos personajes, trasforma el punto de apoyo del naviero en una caja de caudales en la que, además de un saquito con 10.000 (pesetas) lleva escrito: "COMP.[AÑIA]/ TRASATLA[NTICA]/ BANCO/ HISPANO/ COLONIAL/ Ca GENERAL/ DE TABACOS/ FILIPINAS" ${ }^{\prime 3}$. Lo que en el pedestal original está envuelto en la retórica de la alegoría, aquí se expresa en descarnados términos económicos. Un año después, la misma revista vuelve a presentar a Colón reclamando su monumento a Carlos Pirozzini, secretario de la comisión para levantar dicho monumento, que señala al del marqués, que ya tiene el suyo ${ }^{34}$. De forma aún más expresiva se trata el acaparamiento de riqueza de Antonio López, al trasformar su apoyo en un auténtico saco que lleva los siguientes números: "500.000/ 100.000/200"

Sobre el monumento a Colón de Madrid se realizan varias manipulaciones: la esfera del navegante se convierte en queso, la bandera en paraguas, utiliza la cuerda para subir una cesta hasta lo alto del pedestal y otras más ${ }^{36}$. Con frecuencia, este tipo de deformaciones caricaturescas han de entenderse como juicios estéticos de urgencia, como sucedió en Barcelona cuando se dieron a conocer las piezas que iban a formar parte del monumento al navegante ${ }^{37}$. Hay bastantes más en relación con la presencia en exposiciones. Cuando se mostró la estatua de Jacinto Ruiz, de Benlliure, en la exposición nacional de 1890 se publicó una caricatura en la que se exagera su gesto, convirtiéndole en un malabarista circense ${ }^{38}$. Se critica la estatua de Lope de Haro, también de Benlliure, por su aspecto sobrecargado y exceso de aditamentos: "Un guerrero con patas de elefante de la compra regresa muy campante" ${ }^{\prime 3}$. Algunas de las piezas presentadas

31 El Pájaro Azul, 16 de noviembre de 1861.

${ }^{32}$ El Pájaro Verde, $1860, n^{\circ} 1$, s. p. Recuerda la maqueta de Ramón Acín expuesta en la galería Dalmau de Barcelona en 1929, convertida en "monumento" en el parque Miguel Servet de Huesca.

${ }^{33}$ L'Esquella de la Torratxa, 8 de diciembre de 1883.

${ }^{34}$ L'Esquella de la Torratxa, 19 de diciembre de 1884.

${ }_{35}$ L'Esquella de la Torratxa, 14 de octubre de 1892. CADENA, J. M.: Barcelona vista..., op. cit., p. 56.

${ }^{36}$ La caricatura, 25 de mayo de 1884. Llevan la firma de Joaquín Moya y Ángeles.

${ }^{37}$ L'Esquella de la Torratxa, 25 de mayo de 1883.

${ }^{38}$ La Avispa, 15 de mayo de 1890. El monumento fue inaugurado en 1891 en la plaza del Rey de Madrid.

${ }^{39}$ El monumento fue inaugurado en 1890 en la plaza Nueva de Bilbao. Desde 1940 está en la plaza Circular. 
para levantar un monumento a Rius i Taulet en Barcelona también fueron caricaturizadas (Figura 3). La que llevaba el número 4 se retituló "El altar del sacramento", por su parecido con una altar. El proyecto ganador, que figuró con el número 9, se reinterpretó como "Panteón de primera clase". La figura de Barcelona que corona al alcalde se reinterpretó como la viuda que limpia la tumba. El número 8 se retituló "Traslado de un piano al cuarto piso": cuatro porteadores sostienen el instrumento musical. El número 12, "Reloj de sobremesa", al que un ama de casa daba cuerda ${ }^{40}$. Cuando se expuso el boceto del monumento a Ganivet de Juan Cristóbal en la Nacional de 1920, la parte delantera, donde un joven desnudo sostiene un macho cabrío, se reprodujo con un globo que sale de la boca de este personaje: "Con la piel de este cabrito me hago yo por lo menos un chaleco"41.

Los pedestales fueron objeto reiterado de reinterpretación. Se exagera la supuesta inestabilidad del de Serafí Pitarra, que puede hacerle caer ${ }^{42}$. En una parodia del entierro del arquitecto Pere Falqués, autor del mismo, desfila el monumento, como una exagerada forma ondulante ${ }^{43}$. También en otra caricatura de $\mathrm{Cu}$-Cut ${ }^{44}$. Esa forma sugiere el número $\operatorname{dos}^{45}$. También la altura de la columna del monumento a Colón sugiere la posibilidad de que se curve, por lo que Colón teme caerse ${ }^{46}$. El monumento a Iscle Soler es reinterpretado como una chimenea ${ }^{47}$ y el de Milà i Fontanals como si fuese un dulce ${ }^{48}$.

\section{MUTACIONES}

El monumento a Colón de Barcelona es, por su importancia representativa en el ámbito urbano, uno de los que más mutaciones sufre en la caricatura con la intención de aludir a los más diversos problemas locales y nacionales ${ }^{49}$. La mutación suele estar en relación con una cuestión política de actualidad. Gedeón parodia el

${ }^{40}$ L'Esquella de la Torratxa, 2 de julio de 1897, pp. 404-405.

${ }^{41}$ El Mentidero, 5 de junio de 1920, p. 8. El monumento fue inaugurado en 1921 en la colina de la Alhambra en Granada.

${ }^{42} L^{\prime} A v i, 9$ de enero de 1907.

43 L'Esquella de la Torratxa, 29 de octubre de 1909.

${ }^{4}$ Cu-Cut!, 2 de noviembre de 1911.

${ }^{45}$ L'Avi, 8 de enero de 1907. Ilustración de Josep Robert i Picarin. Explícitamente como un dos aparece en L'Esquella de la Torratxa, 29 de julio de 1938, p. 479.

${ }^{46}$ L'Esquella de la Torratxa, 29 de agosto de 1902. Ilustración de Josep Robert i Picarín. CADENA, J. M.: Barcelona vista ..., op. cit., p. 15.

${ }^{47}$ L'Esquella de la Torratxa, 26 de abril de 1918, p. 277. CADENA, J. M.: Barcelona vista..., op. cit., p. 45.

${ }^{48}$ Cu Cut!, 14 de mayo de 1905. Ilustración de Joan García Junceda. CADENA, J. M.: Barcelona vista..., op. cit., p. 41.

49 REYERO, C.: "Propaganda...", op. cit., pp. 42-46. 
monumento funerario a Colón de Arturo Mélida, hoy en la catedral de Sevilla, y entonces destinado para La Habana, en relación con la pérdida de Cuba en 1898. Lleva el siguiente encabezamiento: "COLON... DESCENDENTE/ (PARODIA DEL MONUMENTO DE MÉLIDA DESTINADO A LA CATEDRAL DE LA HABANA)". En el pie dice: "EL ÚLTIMO REPATRIADO" ${ }^{\circ 0}$. Los cuatro reyes de armas y el féretro llevan el emblema de la Cruz Roja (Figura 4).

En 1908 se caricaturiza el monumento al doctor Federico Rubio, de Blay, como si fuera "Alejandro Pidal cosiendo una sotana para toda España", según dice el pie, y con esta inscripción en el pedestal: "AL SERÁFICO DOCTOR/ PIDAL/ QUE COBRÓ MÁS SUELDOS QUE NADIE. SUMMA THEOLOGICA 750.000/ ANUALES" ${ }^{51}$. Utiliza el parecido físico entre el político, que tuvo diferentes cargos públicos durante la Restauración, y el médico. La crítica hace alusión a su obra sobre Santo Tomás de Aquino, al que dedicó gran atención durante toda su vida, a los cargos que tuvo y a su papel de portavoz de los intereses eclesiásticos.

En Barcelona, Alejandro Lerroux se trasforma en Neptuno ${ }^{52}$; y, en Sevilla, los hermanos Quintero, que estrenaron en 1910 La rima eterna, cuyas ganancias se destinaron a levantar el monumento a Bécquer, aparecen junto al boceto del mismo, convertido en una especia de bibelot, entre los dos escritores. El pie vuelve a aludir al sentido "vivo" del homenajeado: "embozados en su capa... iEn Sevilla! ¡Se va a asar el pobrecito!”53 (Figura 5).

\section{CONCLUSIONES}

Los motivos que llevan a actuar sobre los monumentos de forma caricaturesca se encuadran en tres niveles, antropológico, estético y político. En primer lugar, el arte corre el mismo riesgo de burla que todo aquello que, en una práctica social, está sacralizado. En la medida que "la alta cultura

${ }^{50}$ Gedeón, 6 de octubre de 1898. Firmado por Pedro Antonio Villahermosa, Sileno. Los restos de Colón se encontraban depositados en La Habana. El gobierno de Sagasta autorizó su traslado. El asunto ocupó a la prensa, mezclado con las noticias sobre los repatriados.

${ }^{51}$ Gedeón, 20 de mayo de 1904. El monumento fue inaugurado en 1906 el parque del Oeste de Madrid.

${ }^{52} \mathrm{Cu}$-Cut!, 25 de agosto de 1910. CAPDEVILA, J. (coord.): Cu-Cut! Sátira política..., op. cit., p. 39.

${ }_{53}$ Gedeón, 27 de noviembre de 1910. Firmado por Fernando Gómez-Páramo del Fresno, dibujante que realizó muchas caricaturas relacionadas con el mundo del teatro. Se reproduce y documenta la promoción de los Quintero en relación con el monumento en la excelente monografía de PALENQUE, Marta: La construcción del mito Bécquer. El poeta en su ciudad, Sevilla, 1871-1936. Sevilla, 2011, p. 165. 
del siglo XIX no era nada si no incorporaba lo permanente, lo indisputable e ideal" ${ }^{54}$ se favorecieron, paralelamente, subculturas antitéticas, presididas por lo pasajero, lo discutible y lo vulgar. En ese sentido, la caricatura ocupa un espacio irrenunciable. El crítico José Francés admitía que la pintura seria puede ser reaccionaria, en tanto que contribuye "a que se mantengan los valores reconocidos como intangibles por la multitud; pero la pintura satírica debe ser siempre revolucionaria, inquieta, un poco desvergonzada y arbitraria" ${ }^{55}$. La broma es siempre un desahogo, una necesidad de destensar la vida, que resulta irreprimible ${ }^{56}$. Solo lo importante se caricaturiza, así que, en sí mismo, supone una prueba de la relevancia de los monumentos como objetos valiosos desde el punto de vista funcional. Parodiarlos constituye una suerte de conjura sobre la imposición que, en ese sentido, ejercen sobre las ideas y el gusto.

En segundo lugar, las caricaturas no deben ser juzgadas solo como unos productos visuales más, sino en relación con la resonancia que alcanzaron en virtud de la mirada estética sobre lo caricaturizado. Puede decirse que hacen crítica de arte en términos plásticos. En ese sentido, la caricatura funciona como una mediación. Revelan formas de interpretar y de recordar los monumentos que no tienen que ver con la retórica solemne de quienes los conciben. Por tanto, cuestionan el monumento y frivolizan su mensaje. En algunos casos puede considerarse un mecanismo de contrapropaganda o, incluso, un ejercicio de antimemoria. La mayor parte de las veces, no obstante, la tarea del caricaturista oscila entre el aprovechamiento de los prejuicios existentes sobre formas y mensajes, que tienden a ser potenciados, y el oportunismo de la circunstancia, en la medida que el humor siempre tiene una dimensión coyuntural y arbitraria.

En tercer lugar, la caricatura de monumentos sirvió a la crítica política, lo que demuestra sus posibilidades mediáticas y polémicas. En la medida que una de las razones de la caricatura es desacreditar decisiones del poder, la parodia monumental funcionó como munición. No solo se recurrió a la escultura pública, sino a cualquier monumento, en la medida que el siglo XIX recalificó de tal todo edificio u objeto del pasado merecedor de respeto y memoria. En Sevilla, fueron utilizados, por ejemplo, para ridiculizar a quienes, en nombre del progreso, no respetaban el patrimonio: ante la campaña de derribos, entre otros las puertas de la muralla, que llevaba a cabo el Ayuntamiento a mediados del siglo XIX, la Giralda y el Archivo de Indias, convertidos en monumentos andantes, se preparan para marcharse de la ciudad: "Pues que tocan

${ }^{54}$ CROW, Thomas: El arte moderno en la cultura de lo cotidiano. Madrid, 2002, p. 32.

${ }^{55}$ FRANCÉS, José: "La caricatura contemporánea", Madrid Cómico, 89, 28 de octubre de 1911.

${ }^{56}$ BURKE, Peter: Formas de historia cultural. Madrid, 2000, pp. 124-125. 
a tarára/ Con antiguos edificios/ Por si estorbamos nosotros,/ Nos vamos, y... ¡abur, Perico!" 57 . A ver quién no se implica.

Fecha de recepción: 1 de diciembre de 2016

Fecha de aceptación: 19 de enero de 2017

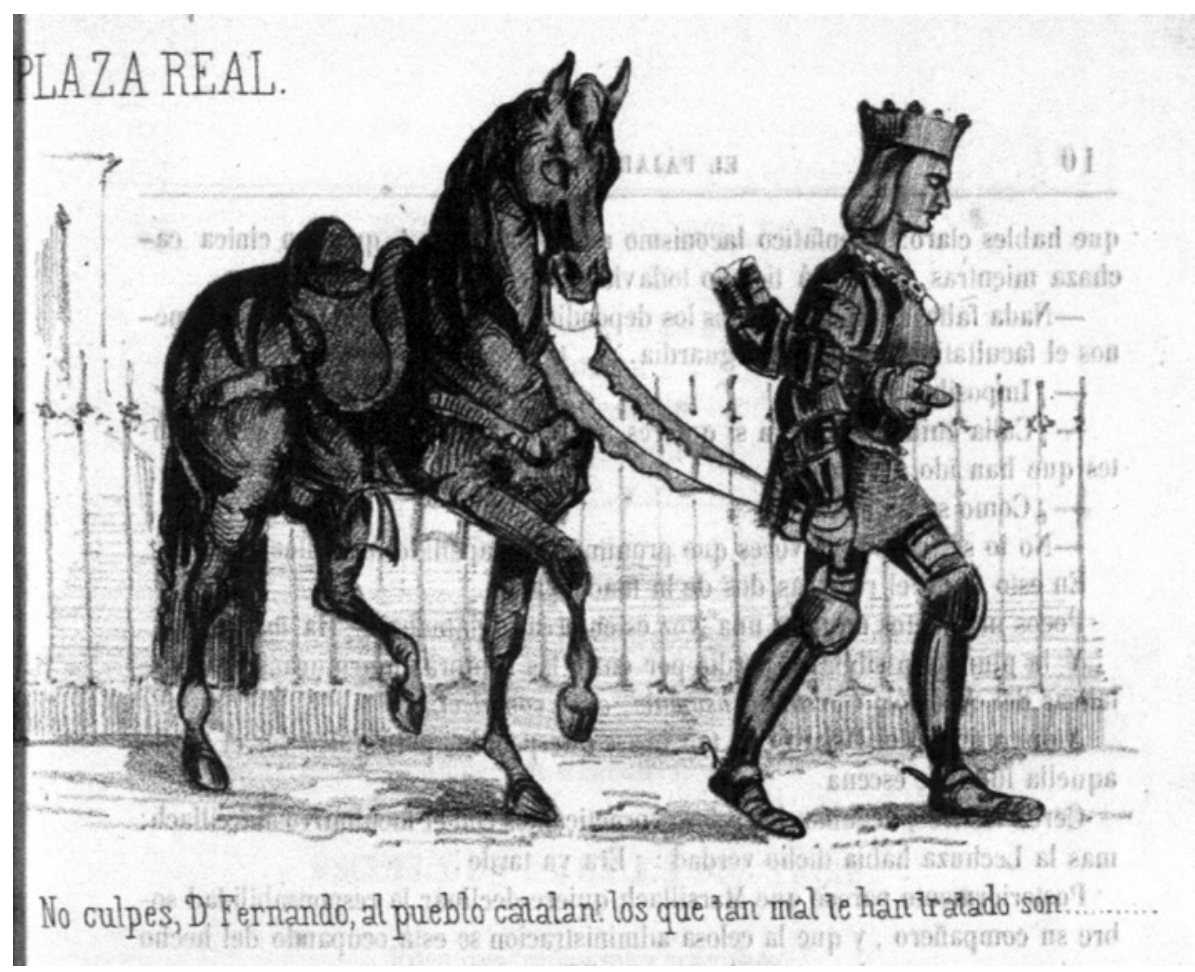

Figura 1. Caricatura del Monumento a Fernando el Católico, Barcelona (El Pájaro Azul, 20 de julio de 1861, p. 9).

${ }^{57}$ Litografía de Luis Mariani. El Tío Clarín, 22 de agosto de 1864. 


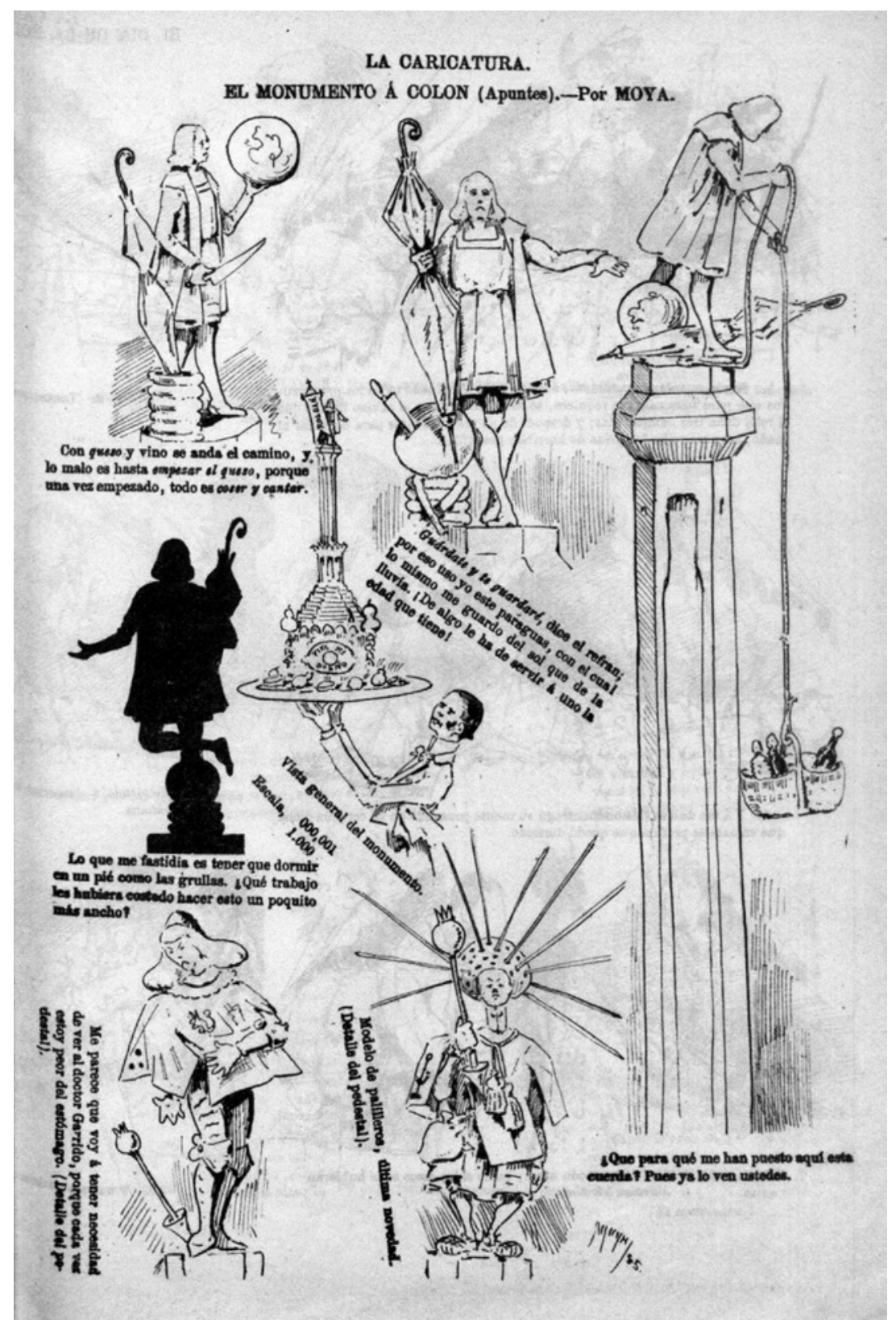

Figura 2. Joaquín Moya, Caricaturas del monumento a Colón, Madrid (La Caricatura, 25 de mayo de 1885, p. 4). 

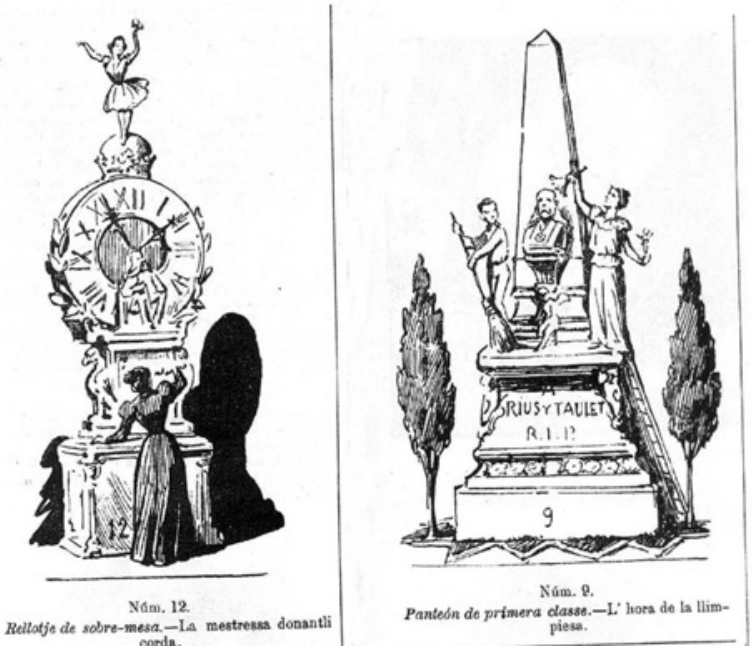

Figura 3. Caricaturas de proyectos presentados al concurso para levantar un monumento a Rius i Taulet, Barcelona (L'Esquella de la Torratxa, 2 de julio de 1897, pp. 404-405).

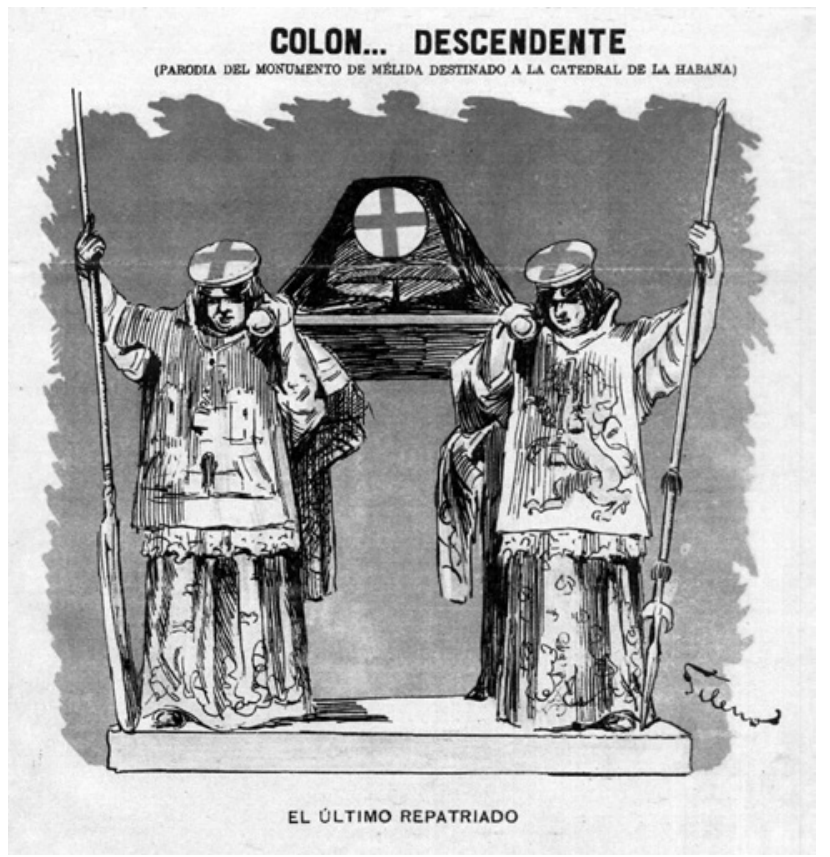

Figura 4. Pedro Antonio Villahermosa, Sileno, Caricatura del monumento a Colón, Sevilla (Gedeón, 6 de octubre de 1898, p. 1). 


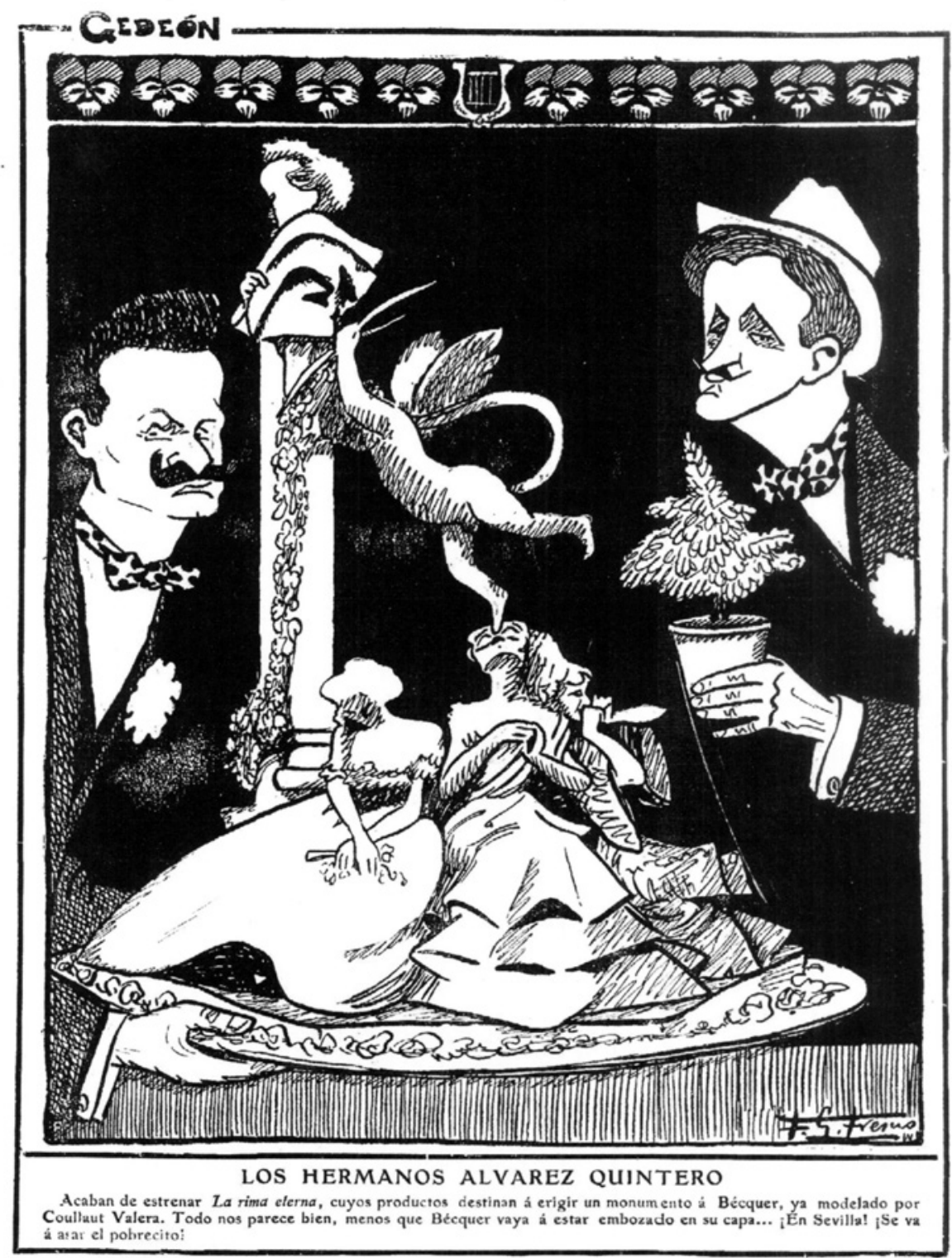

Figura 5. Fernando Gómez Páramo del Fresno, Caricatura del monumento a Bécquer, Sevilla (Gedeón, 27 de noviembre de 1910, p. 7). 